Original Research Paper

\title{
Penerapan Sekolah Sehat dan Taat Hukum Pasca Pembelajran Daring di SDN 62 Kabupaten Lebong Provinsi Bengkulu
}

\author{
Bintang Agustina Pratiwi ${ }^{1 *}$, Rangga Jayanuarto ${ }^{2}$, Wetti ${ }^{3}$, Ayu Maharani $^{4}$, Essy Tuwi Susanti ${ }^{5}$ \\ ${ }^{1,3,5}$ Fakultas Ilmu Kesehatan, Universitas Muhammadiyah Bengkulu, Bengkulu, Indonesia; \\ ${ }^{2,45}$ Fakultas Hukum, Universitas Muhammadiyah Bengkulu, Bengkulu, Indonesia
}

https://doi.org/10.29303/jpmpi.v3i2.1140

Sitasi: Pratiwi, B. A., Jayanuarto, R., Wetti., Maharani, A \& Susanti, E. T. (2021). Penerapan Sekolah Sehat dan Taat Hukum Pasca Pembelajran Daring di SDN 62 Kabupaten Lebong Provinsi Bengkulu. Jurnal Pengabdian Magister Pendidikan IPA 4(4)

Article history

Received: 10 Oktober 2021

Revised: 30 Oktober 2021

Accepted: 17 November 2021

*Corresponding Author: Bintang Agustina Pratiwi, Prodi

Kesehatan Masyarakat, Fakultas

Ilmu Kesehatan Universitas

Muhammadiyah

Bengkulu,Bengkulu;

Email:bintangagustina@umb.ac.id

\section{Pendahuluan}

Sejak meningkatnya kasus covid 19, pemerintah memutuskan seluruh aktivitas keluar rumah dibatasi termasuk kegiatan belajar mengajar. Pembelajaran daring menuntut tenaga pengajar dan siswa menguasai teknologi. Berbagai dampak dari penerapan pembelajaran daring yang ditemukan yaitu masih minimnya penguasaan teknologi, pengeluaran biaya semakin meningkat untuk kuota internet, tugas tambahan bagi orang tua untuk mendampingi anak, berkurngnya komunikasi antar siswa, siswa dengan guru, antar guru, orang tua dan

\begin{abstract}
Penurunan kasus covid 19 mendukung pengaktifan kembali pembelajaran tatap muka. Sejak belajar dari rumah lingkungan sekolah kurang mendapatkan perhatian. Selain itu selama belajar di rumah anak lebih terpapar dengan teknologi yang berdampak pada pengaruh negative tentang narkotika, bullying dan berita-berita hoaks. Tujuan dari kegiatan ni adalah tercipta Kembali sekolah sehat dan seluruh siswa memahami tentang hukum. Kegiatan dilakukan dengan metode penyuluhan dan hukum. Pelaksanaan dilakukan selama satu bulan di SDN 62 Kabupaten lebong Provinsi Bengkulu. Sasaran dari kegiatan ini adalah siswa/i SD 62. Hasil kegiatan menunjukkan adanya perubahan perilaku siswa seteah dilakukan edukasi, siswa juga ikut berperan serta dalam menciptakan lingkungan sekolah yang sehat, menjaga kesehatan diri selama pandemi. Di bidang hukum siswa mengetahui bahaya narkotika serta hukuman bagi pengguna dan pengederanya. Selain itu siswa juga memahami bahwa bullying merupakan salah satu tindakan criminal. Cara agar tidak erpengaruh berita hoak dan tidak ikut serta dalam menyebarkan berita hoaks. Sebaiknya kegiatan ini terus dilakukan secara berkala agar sekolah tetap sehat dan siswa nya taat akan hukum.
\end{abstract}

Keywords: Sekolah Sehat, Taat Hukum

jam kerja yang meningkat karena harus berkoordinasi dengan siswa, orang tua, guru lain dan kepala sekolah (Purwanto et al., 2020).

Pembelajaran online juga menuntut peran aktif dari para guru dalam menyampaikan materi pembelajaran, tugas dan memberikan umpan balik terhadap tugas yang diberikan. Guru juga harus bisa merancang metode pembelajaran yang dapat menarik minat siswa. Komunikasi yang baik antara guru, siswa dan orang tua sanagt diperlukan untuk tercapainya tujuan dari pembelajaran. Persepsi kesepian muncul dari siswa ketika pembelajaran dilakukan secara daring, karena siswa sudah 
terbiasa betatap muka secara langsung dengan guru dan teman-teman (Kaufmann \& Vallade, 2020).

Pembelajaran dengan model kooperatif tepat digunakan pada masa pandemic covid 19. Siswa diajak untuk membangun pengetahuan secara mandiri. Pada pembelajaran model kooperatif guru berperan sebagai fasilitator yang memfasilitasi siswa untuk mendaptkan ilmu pengetahuan, sehingga peran guru tidak mendominasi (Silalahi, Hakimi, \& Lismidiati, 2018).

Sebuah studi menemukan bahwa covid 19 berdampak pada angka putus sekolah, sebesar $87,42 \%$ siswa putus sekolah pada masa pandemi (Darmayanti, Subarkah, Anunggilarso, \& Suhaman, 2021). Selain itu pembelajaran daring berpengaruh terhadap psikologis siswa, ditemukan hanya $41 \%$ siswa yang mampu secara fisik dan mental mengikuti pembalajaran daring (Baticulon et al., 2021).

Pembelajaran online juga berdampak pada peningkatan perilaku cyberbullying siswa, intensitas penggunaan teknologi semakin meningkat. Kurangnya pengawasan dari orang tua berdampak pada penyalahgunaan teknologi. Ketika seseorang dengan sengaja memosting sesuatudi media sosial yang menyudutkan seseorang dan hal tersebut dilakukan secara terus menerus, sehingga menjatuhkan harga diri seseorang dapat dikatakan termasuk cyberbullying. Selain itu penyebarluasan informasi hoaks juga termasuk dalam cyberbullying (Ruliyatin \& Ridhowati, 2021).

Adapun bentuk bullying yang terjadi pada siswa dalam bentuk verbal dan siswa perempuan sebagai korban (Pratiwi, Herlina, \& Utami, 2021). Dampak dari perilaku cyberbullying ini yaitu anak menjadi minder, dpresi, pemalu, penurunan prestasi, bahkan sampai dengan mengakhiri hidupnya (Ruliyatin \& Ridhowati, 2021 dan Rahayu, 2013)

Selain itu efek lain dari pembelajaran daring adalah sedikitnya waktu belajar dan lebih banyak waktu bermain atau aktivitas lain di luar rumah. Menurut data kasus dari Satresnarkoba Polres Lebong, pada tahun 2021 sudah menangani 12 perkara penyalahgunaan narkotika dengan 16 tersangka yang $60 \%$ tersangka merupakan usia remaja. Hal ini menunjukkan bahwa kurangnya pengetahuan hukum tentang penyalahgunaan narkotika dikalangan anak sekolah atau remaja di Kabupaten Lebong.
Mengaktifkan pembelajaran secara luring/offline sangat baik bagi siswa karena siswa bisa berinteraksi langsung dengan guru dan temannya. Namun tetap perlu adanya pengawasan, karena kemampuan siswa dalam menggunakan teknologi juga semakin meningkat.

Permasalahan lain dari penerapan pembelajran online adalah kesiapan kesehatan lingkungan sekolah dan siswa itu sendiri. Sekolah perlu mendapatkan pendampingan sekolah sehat di masa pandemi covid 19. Edukasi tentang Perilaku Hidup bersih dan Sehat (PHBS) di anggap mampu meningkatkan pengetahuan dan kesadaran masyarakat dalam menerapkan hidup sehat (A et al., 2021)

Kesehatan lingkungan sekolah kurang mendapatkan perhatian selama pembelajaran dilakukan secara daring. Saat ini siswa/i SDN 62 kabupaten lebong sudah berangsur menerapkan pembelajaran tatap muka. Agar kesehatan lingkungan sekolah terpelihara tim mengajak para siswa untuk menerapkan sekolah sehat dan memberikan edukasi tentang PHBS di sekolah.

\section{Metode}

Pengabdian dilakukan setelah pemerintah daerah sudah mengizinkan kepada seluruh sekolah untuk melakukan kegiata pembelajaran secara tatap muka, meskipun tatap muka yang dilakukan oleh pihak sekolah belum bisa dilakukan seperti biasanya sebelum pandemi covid 19. Kegiatan ini bertujuan untuk menciptakan lingkungan sekolah yang sehat dan taat hukum pasca pembelajaran daring.

Bentuk kegiatan pengabdian kepada masyarakat berupa kegiatan penyuluhan tentang kesehatan dan hukum, praktik membersihkan lingkungan sekolah dan mengaktifkan kembali tanaman obat di sekolah, mengajak siswa untuk menerapkan perilaku hidup bersih dan sehat.

Media yang digunakan dalam kegiatan ini bervariasi, terdiri dari media audio visual dan visual. Pada saat penyuluhan tim menjelaskan dengan bantuan power poin yang disampaikan di depan kelas serta melakukan pemutaran video edukasi. Kegiatan praktik dilakukan bersama-sama dengan siswa/i SDN 62 berupa melakukan kebersihan sekolah, senam bersama, praktik cuci tangan dan PHBS.

Waktu pelaksanaan dilakukan selama satu bulan mulai tanggal 26 Agustus - 28 September 
2021. Lokasi kegiatan pengabdian kepada masyarakat yaitu di desa tabeak beleau II Kecamatan Pelabai Kabupaten Lebong Provinsi Bengkulu.

Manfaat dari kegiatan pengabdian masyarakat ini adalah meningkatkan pemahaman siswa tentang kesehatan dan hukum. Selain itu menciptakan lingkungan sekolah yang sehat setelah pembelajaran daring.

\section{Hasil dan Pembahasan}

Pengabdian kepada masayarakat yang dilaksanakan di SDN 62 Kabupaten Lebong dihadiri oleh siswa/i. Pada setiap kegiatan siswa/i berperan aktif untuk mewujukan sekolah sehat. Hal ini terlihat dari semangat siswa dalam setiap kegiatan-kegiatan yang dilakukan.

Selama pembelajaran daring sekolah belum pernah mendapatkan edukasi tentang kesehatan dan hukum. Mengingat saat ini kita masih dalam kondisi pandemic covid 19 dan pembelajaran mulai dilakukan secara luring/tatap muka maka kesehatan sekolah perlu dipersiapkan agar kesehatan siswa/I terjamin.

Selain itu sejak pembelajaran dilakukan daring siswa banyak terpapar oleh handphone, terkadang siswa/I terjadi penyalahgunaan media komunikasi selama siswa/I melakukan pembelajaran daring. Siswa lebih mudah mengakses informasi-informasi yang belum terbukti kebenarannya. Siswa juga masih belum mengerti aturan hukum dalam bersosial media.

Berbagai jens kegiatan yang dilakukan di sekolah terdiri dari :

1. Edukasi

Informasi kesehatan yang diberikan kepada para siswa/i SDN 62 kabupaten lebong yaitu tentang Perilaku Hidup Bersih dan Sehat (PHBS) di sekolah. Terdiri dari ; (1) Mencuci tangan dengan air yang mengalir dan menggunakan sabun, (2) Mengkonsumsi jajanan sehat di kantin sekolah (3) Membuang sampah pada tempatnya, (4) Menggunakan jamban yang bersih dan sehat, (5) Olahraga yang teratur dan terukur, (6) Memberantas jentik nyamuk, (6) Tidak merokok di sekolah, (8) Menimbang berat badan dan mengukur tinggi badan setiap 6 bulan.

Banyak cara yang bisa dilakukan untuk menciptakan lingkungan sekolah yang sehat, sosialisasi pemanfaatan toga di sekolah dan praktik membuat sabun batangan berbahan alami juga bermanfaat untuk sekolah. Setelah siswa diajarin untuk membuat sabun batangan, selanjutnya siswa dilatih cara mencuci tangan yang baik dan benar (Sunarwidhi, Wirasisya, \& Hanifa, 2020).

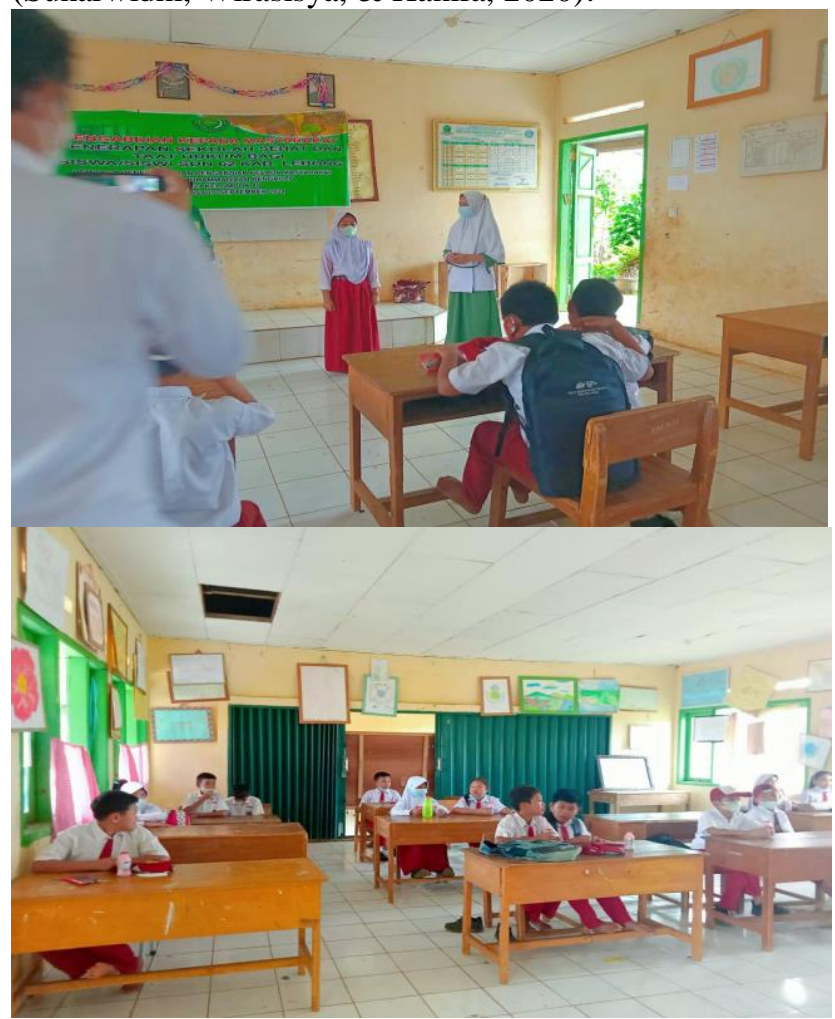

Gambar 1. Edukasi tentang PHBS di sekolah

Selama ini para siswa hanya mencuci tangan tanpa menggunakan sabun dan tanpa mengikuti Langkah-langkah mencuci tangan yang baik dan benar.

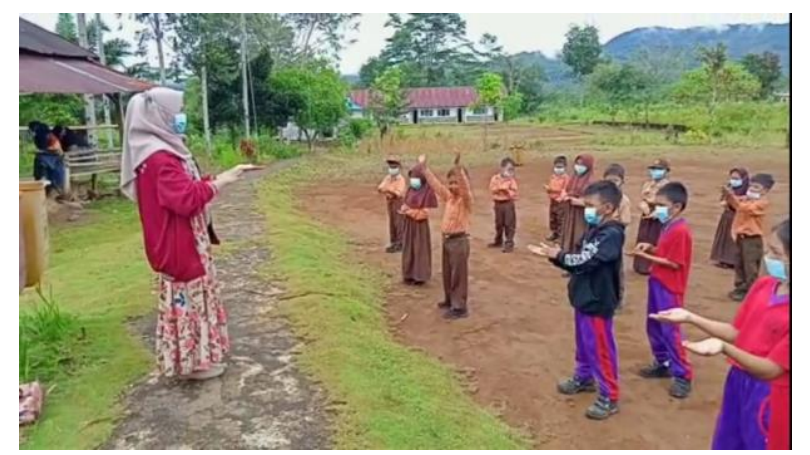

Gambar 2. Kegiatan edukasi enam Langkah cuci tangan

Setelah dilakukan edukasi enam langkah mencuci tangan siswa lebih memahami langkah-langkah mencuci tangan yang baik dan benar. 

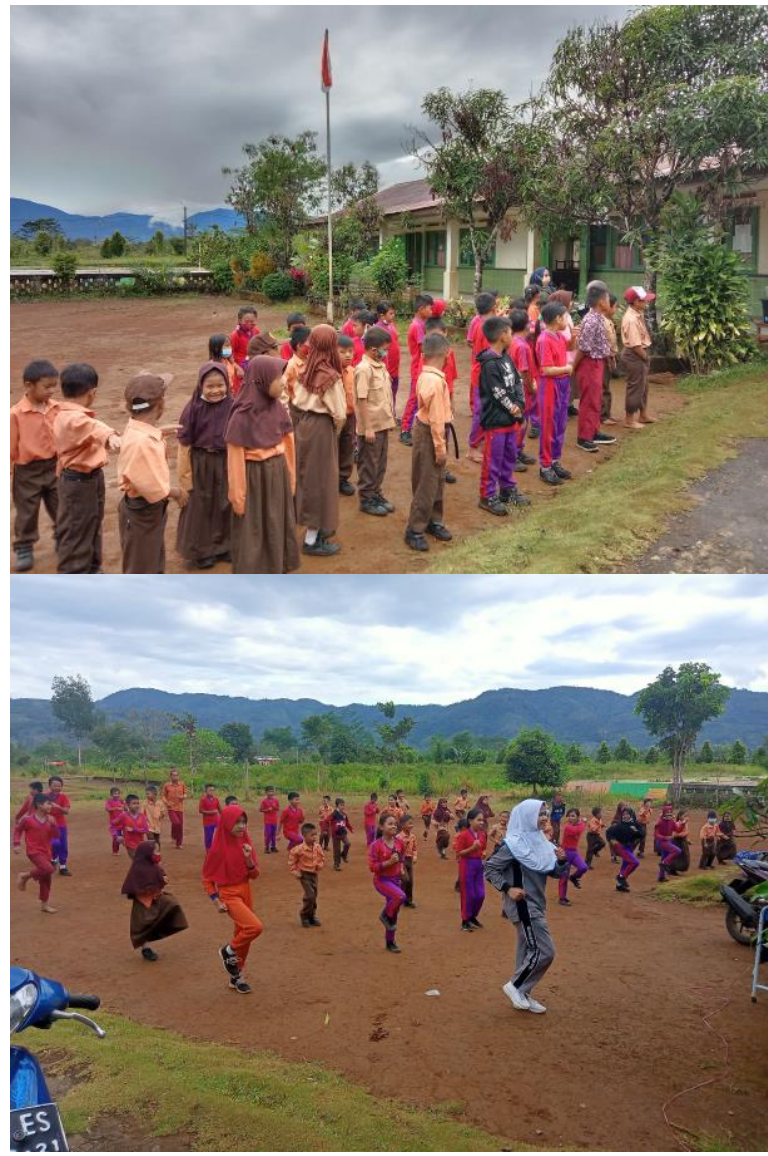

Gambar 3. Olahraga secara teratur

Seluruh siswa di SDN 62 kabupaten lebong wajib menggunakan masker selama berada di sekolah. Siswa juga melaksanakan kegiatan olahraga setiap pagi sambil berjemur untuk mengaktifkan vitamin D. Selama kegiatan pengabdian kepada masyarakat berlangsung, seluruh siswa mengikuti kegiatan olahraga setiap hari sabtu.

Penerapan PHBS kepada anak diterapkan sejak dini, hal ini dilakukan agar anak terbiasa dengan pola hidup sehat. Peran orang tua sangat diperlukan untuk menciptakan kebiasaan yang sehat. Ketika anak sudah terbiasa menerapkan PHBS di rumah, mudah bagi anak untuk menerapkan PHBS di lingkungan sekolah (Rachmawaty, Maulidiah, \& Utama, 2021).

Siswa juga melakukan aktivitas fisik setiap pagi untuk mendapatkan tubuh yang bugar, dengan melakukan olahraga secara rutin dapat meningkatkan daya tahan tubuh siswa. Baik orang sehat maupun yang sakit (terinfeksi covid 19) jika tidak memiliki gejala yang berat dianjurkan tetap melakukan olahraga (Furkan, Rusdin, \& Shandi, 2021).

Setelah informasi kesehatan diberikan selanjutnya siswa diberikan informasi tentang penyalahgunaan narkotika, bullying dan penyebaran informasi hoaks. Pemilihan materi berdasarkan temuan bahwa sejak pembelajaran daring, siswa/i terpapar dengan media social melalui handphone. Siswa/i bebas mengakses segala infomasi baik itu informasi yang bersifat positif dan informasi yang bersifat negative. Bagi orang tua siswa yang bekerja sangat sulit untuk melakukan pengawasan penggunaan handphone.

Edukasi tentang dampak hukum dari penggunaan narkotika, perilaku bullying dan penyebaran informasi hoaks diberikan kepada siswa, karena saat ini banyak anak-anak usia sekolah dasar ditemukan sudah mengkonsumsi rokok dan menghirup aibon. Melalui handphone anak-anak saling berkomunikasi dan melakukan tindakan bullying, candaan yang melampui batas dianggap merupakan hal biasa. Padahal Tindakan yang dilakukan merupakan tidakan yang menyudutkan salah satu pihak.

Beredarnya informasi-informasi hoaks dikalangan anak-anak memberikan dampak negarif. Anak-anak adalah sosok yang masih polos serta kondisi emosional yang masih labil. Ketika mendapatkan informasi yang bertolak belakang dengan kebiasaannya maka anak-anak cenderung menolak dan mencari teman yang memiliki pemikiran yang sama. Sehingga menyebarkan informasi itu kepada temannya, padahal informasi yang diterimanya belum pasti kebenarannya.

Seluruh siswa/i aktif dalam kegiatan edukasi kesehatan dan hukum. Mereka bersedia ikut berperan dalam mencegah penggunaan narkotika, bullying dan penyebaran informasi hoaks.

Perilaku bullying umumnya dilakukan oleh anak laki-laki terhadap anak perempuan. Bullying verbal yang dilakukan disekolah berdampak pada prestasi siswa dan psikologis siswa (Pratiwi et al., 2021). Edukasi dapat meningkatkan pemahaman siswa tentang bullying, terbukti ada perbedaan pengetahuan siswa tentang bullying sebelum dan setelah 
diberikan edukasi (Heryani, Asmuni, \& Nasution, 2020).

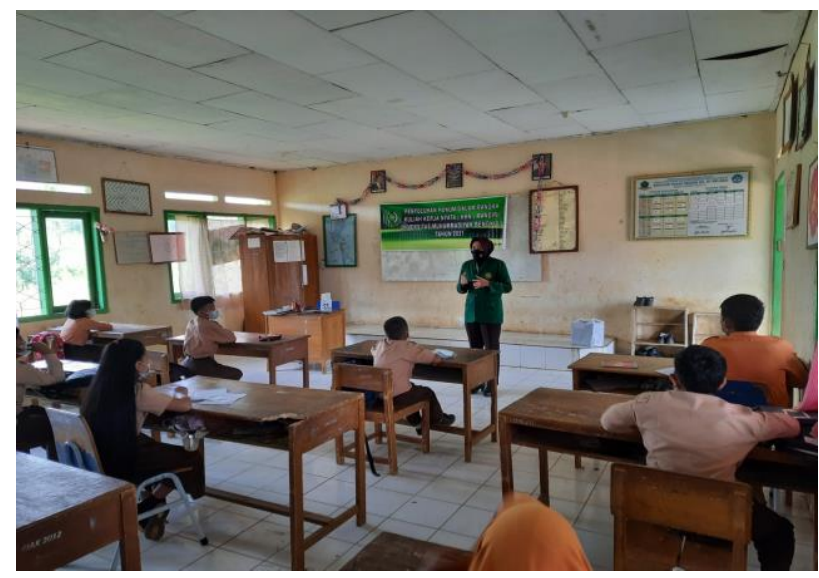

Gambar 4. Edukasi tentang Hukum

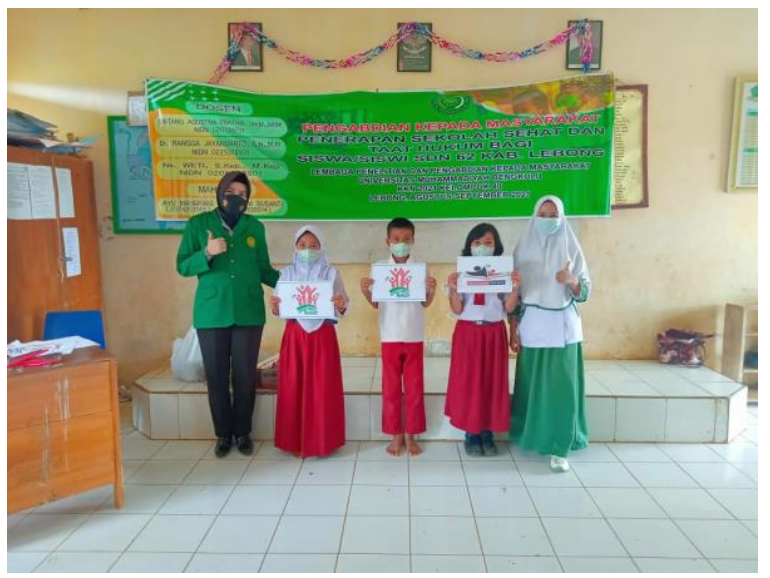

Gambar 4. Partisipasi siswa dalam menolak Narkotika, Bullying dan informasi hoaks

Sejalan dengan kegiatan yang dilakukan oleh tim pengabdian lainnya untuk meningkatkan kesadaran hukum perlu adanya edukasi. Pendidikan karakter yang diberikan kepada seseorang mampu meningkatkan kesadaran seseorang tentang hukum (Putra et al., 2021).

Banyak remaja belum sadar akan perulaku cyberbullying sehingga aktivitas tersebut dianggap biasa saja, termasuk juga penyebarluasan informasi yang belum bisa dipastikan kebenarannya. Pemberian edukasi kepada siswa, guru, orang tua dan masyarakat perlu dilakukan untuk meningkatkan pemahaman dan kesadaran semua pihak.
Pengetahuan yang baik tentang cyberbullying dianggap mampu mencegah timbulnya perilaku bullying (Utari Listiadisti Ayi, 2020).

2. Praktik

Untuk mewujudkan lingkungan sekolah yang sehat peran serta dari seluruh siswa sangat diperlukan. Pelaksana pengabdian kepada masayarakat dan siswa melakukan kegiatan gotong royong membersihkan perkarangan sekolah.

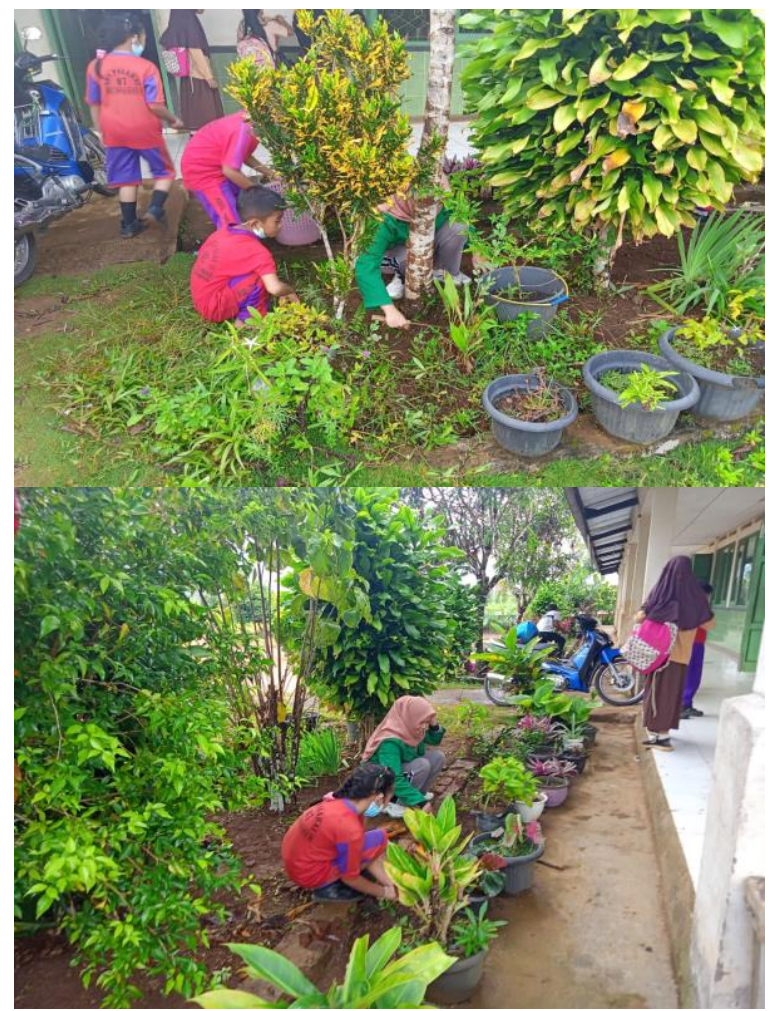

Gambar 5 Kegiatan membersihkan lingkungan SDN 62 Kabupaten Lebong

Lingkungan sekolah bersih dan sehat akan mendukung kesehatan sumber daya manusia yang ada di dalam nya. Selama angka kasus covid 19 meningkat seluruh aktivitas pembelajaran dilakukan secara online. Baik guru maupun siswa melakukan komunikasi pembelajaran melalui social media. Sejak aktivitas di sekolah terhenti, lingkungan sekolah menjadi tidak tertata kebersihannya. Setelah kegiatan kebersiahan sekolah dilakukan lingkungan sekolah menjadi lebih bersih dan tertata.

Penerapan PHBS dilingkungan sekolah selama pandemi dapat meningkatkan 
kesadaran siswa dan menjamin terpeliharanya kesehatan siswa. Siswa berperan aktif dalam menciptkan lingkungan sekolah yang sehat (Puspitaningsih, Mawaddah, \& Fatmawati, 2020).

\section{Kesimpulan}

Terciptanya lingkungan sekolah yang sehat, serta perilaku sehat yang dilakukan oleh siswa agar kesehatan siswa tetap terjaga. Siswa juga mengetahui dampak narkotika, bullying dan informasi hoaks.

\section{Saran}

Kegiatan pengabdian ini sebaiknya dilakukan secara berkala kepada siswa/I di SDN 62 kabupaten lebong, sehingga dengan dilakukan kegiatan ini kesehatan sekolah tetap terjaga dan siswa terhindar dari narkotika, bullying dan informasi hoaks.

\section{Ucapan Terima Kasih}

Penulis mengucapkan terima kasih kepada Universitas Muhammadiyah Bengkulu dan SDN 62 kabupaten lebong yang telah memberikan dukungan hingga kegiatan pengabdian kepada masyarakat berjalan lancer.

\section{Daftar Pustaka}

A, N., Ramadan, A., Jabir, M. I., Fadlan, Ismail, Putri, W. W. D., Utami, R. K., et al. (2021). Pendampingan Perilaku Hidup Bersih dan Sehat (PHBS) Dalam Membangun Gaya Hidup Sehat Sejak Dini Di Masa Pandemi Covid-19. Comunnity Development Journal, 2(3), 708-713. Retrieved from https://journal.universitaspahlawan.ac.id/inde x.php/cdj/article/view/2544

Baticulon, R. E., Sy, J. J., Alberto, N. R. I., Baron, M. B. C., Mabulay, R. E. C., Rizada, L. G. T., Tiu, C. J. S., et al. (2021). Barriers to Online Learning in the Time of COVID-19: A National Survey of Medical Students in the Philippines. Medical Science Educator, 31(2), 615-626. Springer US. Retrieved from https://doi.org/10.1007/s40670-021-01231-z

Darmayanti, I., Subarkah, P., Anunggilarso, L. R., \& Suhaman, J. (2021). Prediksi Potensi Siswa Putus Sekolah Akibat Pandemi Covid-19

\author{
Menggunakan Algoritme K-Nearest \\ Neighbor, 10(2), 230-238.
}

Furkan, F., Rusdin, R., \& Shandi, S. A. (2021). Menjaga Daya Tahan Tubuh dengan Olahraga Saat Pandemi Corona COVID-19. JISIP (Jurnal Ilmu Sosial dan Pendidikan), 5(1), 424-430.

Heryani, N., Asmuni, A., \& Nasution, A. F. . (2020). Pengembangan Aplikasi Strategi Pencegahan Perilaku Perundungan (Bullying) pada Sekolah Dasar di Kota Jambi. Jurnal Akademika Baiturrahim Jambi, 9(2), 190.

Kaufmann, R., \& Vallade, J. I. (2020). Exploring connections in the online learning environment: student perceptions of rapport, climate, and loneliness. Interactive Learning Environments, O(0), 1-15. Taylor \& Francis. Retrieved from https://doi.org/10.1080/10494820.2020.17496 70

Pratiwi, I., Herlina, H., \& Utami, G. T. (2021). Gambaran Perilaku Bullying Verbal Pada Siswa Sekolah Dasar: Literature Review. Jkep, 6(1), 51-68.

Purwanto, A., Pramono, R., Asbari, M., Santoso, P. B., Wijayanti, L. M., Choi, C. H., \& Putri, R. S. (2020). Studi Eksploratif Dampak Pandemi COVID-19 Terhadap Proses Pembelajaran Online di Sekolah Dasar. EduPsyCouns: Journal of Education, Psychology and Counseling, 2(1), 1-12. Retrieved from https://ummaspul.ejournal.id/Edupsycouns/article/view/397

Puspitaningsih, D., Mawaddah, N., \& Fatmawati, Y. A. (2020). Upaya Peningkatan Budaya Perilaku Hidup Bersih Dan Sehat di Lingkungan Sekolah Pada Masa Pandemi Covid-19. Jurnal Abdimakes, 1(1), 28-37. Retrieved from http://ejournal.stikesmajapahit.ac.id/index.php /AMK/article/view/727/727

Putra, P. S., Sutedja, B., Utamidewi, W., Apriani, R., Nurhaedi, N. R., \& Kurniawan, E. R. (2021). Optimalisasi Penggunaan Media Daring Terhadap Pendidikan Berkarakter Dalam Upaya Menciptakan Masyarakat Sadar Hukum. To Maega: Jurnal Pengabdian Masyarakat, 4(2), 100.

Rachmawaty, M., Maulidiah, R., \& Utama, F. (2021). Pembiasaan Perilaku Hidup Bersih dan Sehat Pada Peserta Didik PAUD di Masa 
Pandemi Covid-19. Seminar Nasional Teknologi Pembelajaran, 1(1), 748-759.

Rahayu, F. S. (2013). Cyberbullying Sebagai Dampak Negatif Penggunaan Teknologi Informasi. Jurnal Sistem Informasi, 8(1), 2231. Retrieved from https://jsi.cs.ui.ac.id/index.php/jsi/article/view 1321

Ruliyatin, E., \& Ridhowati, D. (2021). Dampak Cyber Bullying Pada Pribadi Siswa dan Penanganannya Di Era Pandemi Covid-19. Bikotetik (Bimbingan dan Konseling Teori dan Praktik), 5(1), 1. Retrieved from https://journal.unesa.ac.id/index.php/jbk/articl e/view/10921

Silalahi, V., Hakimi, M., \& Lismidiati, W. (2018). Efektivitas Audiovisual dan Booklet sebagai Media Edukasi untuk Meningkatkan Perilaku Skrining IVA. Media Kesehatan Masyarakat Indonesia, 14(3), 304. Retrieved from https://core.ac.uk/download/pdf/289878279.p df

Sunarwidhi, A. L., Wirasisya, D. G., \& Hanifa, N. I. (2020). Sosialisasi Pemanfaatan TOGA Dan Pembuatan Sabun Batang Alami (Sabun Aloe vera) Kepada Murid Yayasan Generasi Muslim Cendekia di Lombok Tengah, Indonesia. Jurnal Pengabdian Magister Pendidikan IPA, 3(2).

Utari Listiadisti Ayi. (2020). Jurnal Menara Medika https://jurnal.umsb.ac.id/index.php/menarame dika/index JMM 2020 p-ISSN 2622-657X, eISSN 2723-6862. Jurnal Menara Medika, 3(1), 54-65. 